\title{
THEORY OF RBE
}

Progress Report

Robert Katz

University of Nebraska

Lincoln, Nebraska

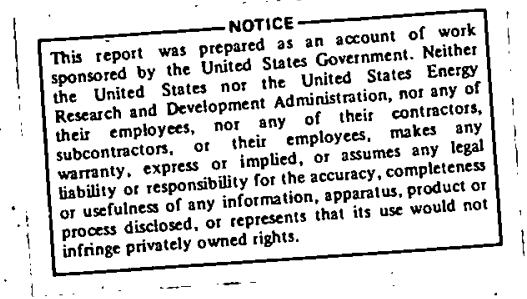

1 January 1975 - 31 December 1975

PREPARED FOR THE ENERGY RESEARCH AND DEVELOPMENT ADMINISTRATION

UNDER CONTRACT NO. AT $(11-1)-1671$

蛋

This report was prepared as an account of work sponsored by the United States Government. Neither the United Stites nor the United States Energy Research and Development Administration, nor any of their employees, nor any of their contractors, makes any warranty, express or implied, or assumes any legal liability or responsibility for the accuracy, completeness, or usefulness of any information, apparatus, product, or process disclosed or represents that its use would not infringe privately owned rights. 


\section{DISCLAIMER}

This report was prepared as an account of work sponsored by an agency of the United States Government. Neither the United States Government nor any agency Thereof, nor any of their employees, makes any warranty, express or implied, or assumes any legal liability or responsibility for the accuracy, completeness, or usefulness of any information, apparatus, product, or process disclosed, or represents that its use would not infringe privately owned rights. Reference herein to any specific commercial product, process, or service by trade name, trademark, manufacturer, or otherwise does not necessarily constitute or imply its endorsement, recommendation, or favoring by the United States Government or any agency thereof. The views and opinions of authors expressed herein do not necessarily state or reflect those of the United States Government or any agency thereof. 


\section{DISCLAIMER}

Portions of this document may be illegible in electronic image products. Images are produced from the best available original document. 


\author{
THEORY OF RBE \\ Abstract \\ for \\ Technical Progress Report \\ USERDA Contract No.AT $(11-1)-1671$
}

September 1975

Calculations from the theory of RBE have been so simplified that $\mathrm{RBE}, \mathrm{D}_{\mathrm{x}}$, and $\mathrm{OER}$ for a mixed radiation environment. (say, pions, neutrons, and gamma-rays) can be calculated with an HP-65 pocket programmable calculator, once equivalent track segment bombardments have been found for the components of the mix, from theory or from experiment.

With a least-squares seeking cemputer program, cellular radiosensitivity parameters have been evaluated (with 95\% confidence imits) for many biologïcal cells for which survival data is availabse at different LET's. Typically there is good agreement with visualiy fitted parameters, with confidence limits ranging from a few percent on up, depending on the quantity and quality of the data. The procedure reveals internal inconsistencies in the data, and may be used as the basis for the design of efficient experiments.

Studies of many-hit nuclear emulsions have been initiated. These emulsions will exhibit RBE-LET properties similar to those of biological cells and tissues, and will be useful as a model system in studies of low-dose and dose-rate effects in radiobiology. A first quantitative result is that Ilford $\mathrm{K}-1$ emulsion is an $8 \pm 1$ or-more hit detector. 
THEORY OF . RBE

\section{Technical Progress Report}

USERDA Contract No. AT (11-1)-1671

September 1975

1. There has been no deviation in program from that proposed in the renewal application, either in technical content or in the level of expenditure. The principal investigator has spent. 0.3 time on the project during the academic year, and 1.0 time on the project during the period 1-30 June 1975.

2. Following is an index of papers and reports

R. Katz and S. C. Sharma, Cellular Survival in a Mixed Radiation Environment, Int. J. Radiat. Biol. 2, 143 (1974).

R. Katz and S. C. Sharma, OER for Mixed Neutrons and Gamma-Rays, British Journal of Radiology 47, 823 (1974).

R. Katz and S. C. Sharma, RBE-Dose Relations for Neutrons and Pions, Phys. Med..Biol. 20, 410 (1975).

R. Katz, B. Fullerton, R.A. Roth, and S. C. Sharma,

Simplified RBE-Dose Calculations for Mixed Radiation Fields, Health Physics (in press).

Bruce G. Fullerton, Jr., RBE-Dose Calculations in a Mixed Radiation Field, Program \# 02955A, HP-65 User Library, Hewlitt Packard Co., Cupertino, California 95014

R. A. Roth, S. C. Sharma; and R. Katz, Systematic Evaluation of Cellular Radiosensitivity Parameters, submitted to Physics in Medicine and Biology.

R. Katz and F. E. Pinkerton, Response of Nuclear Emulsion to Ionizing Radiations, submitted to Nuclear Instruments and Methods. 
Coo-1671-61 R. Katz and F. E. Pinkerton, Particle Tracks in a Special Nuclear Emulsion, Proceedings of the Second Symposium on Neutron Dosimetry in Biology and Medicine II, p.86.5, G. Burger and H. G. Ebert, Eds., Euratom 1975.

Co0-1671-62 R. Katz and F. E. Pinkerton, Response of INuclear Emulsion to Ionizing Radiations, Fifth Symposium on Microdosimetry, Verbania-Pallanza, Sept. 1975.

Co0-1671-63 R. Katz, Third Triennial Report to USERDA, 1 Jan. 1967 to 31 December 1975, Contract No. AT (11-1)-1671. coo-1671-64 This report. 
3. These continuing investigations into the THEORY OF RBE play upon a single set of themes and variations to achieve a unified theory of track structure, a quantitative formulation of the response of different detectors to different incident ionizing radiations. The theory is a heuristic one, leading out to new investigations, new discoveries, new conceptual structures.

The latest result of track theory is the discovery that Ilford K-2 emulsion is an 8-hit detector. To make this identification we have combined our theory of cellular inactivation with our computer simulation of particle tracks in emulsion, to match the appearance of published photographs of heavy ion tracks in the Ilford $\mathrm{K}$ emulsions. Visual pattern recognition suffices to make positive identifications of Ilford K.5 through $\mathrm{K} .0$ and $\mathrm{K}-1$ emulsion as 1-hit detectors, and $\mathrm{K}-2$ as an $8 \pm 1$ hit detector.

We conceive this as an important discovery. It suggests first that we should seek out other solid state defect/impurity detectors as posibly having the same property, for many hittedness implies discrimination against low LET radiations, a threshold-like behavior depending on LET, and supra-linearity. It leads to a new conceptual understanding regarding $\mathrm{RBE}$, ion-kill, and gamma-kill, for these are no longer uniquely biological phenomena. It suggests that emulsions can be used as modeling systems to study Elkind repair (latent image fading), dose-rate, and low dose effects. It suggests the possibility that an emulsion intermediate in desensitization between $\mathrm{K}-1$ and $\mathrm{K}-2$ will have RBE-LET properties paralleling human tissue, when appropriately developed. 
As a result we have bëgun to focus some attention on the properties and development of specially desensitized nuclear emulsions, have procured $K-1, K-1.5$ (specially compounded for us), $\mathrm{K}-2$, and $\mathrm{K}-3$ emulsions, and have initiated the investigations intended to determine their radiosensitivity parameters, and the way that they are affected by fading and processing.

For some time we have been concerned about the subjective character of the assignment of cellular radiosensitivity parameters from the visual fitting of calculated survival curves to experimental data ortained with radiations of different LET, and have sought a more systematic and objective approach to the problem: Recently. we have completed studies of the determination of radiosensitivity parameters through use of a least-squares seeking computer program designed for non-linear systems. The program is provided with the set of experimental. data in the form of surviving fraction vs. a dose at all available irradiations with particles of different charge and energy, with the formulas of the theory, and with an initial set of parameters determined by visual fits. It yields optimal values of the parameters, and 95\%. confidence limits.

For the most carefully developed data, we find the optimal parameters remarkably close to those obtained by visual fitting. In some cases the $95 \%$ confidence limits are in the neighborhood of $5 \%$. Some of the data converges consistently, regardless of the initial set, allowed to range as far as $20 \%$ away from the best visual fits. One cannot go much further because of internal limits in the computer on the size of the numbers it can deal with. In some cases the fact 
that the computer does not converge may be revealing as to the quality of the experimental data. For the best data we find that the computer program gives consistent evaluations of the radiosensitivity parameters even when classes of data are excluded. Thus we have excluded all survival points in the first decade, or all points except those in the second and third decade, or all bombardments except those for $\mathrm{z}=1,5$, and 9 , or even all bombardments except for these values of $z$ and lying in the second and third decade of survival. Where there is sufficient initial data to undertake these exercises, as in the data of powers et al. forbacterial spores, and skarsgard et al., for chinese hamster cells, we find that we can use $10 \%$ of the data to get parameters within 5-20\% of the optimal values from the complete set of data. Not only do we find that the theory is very consistent with the experimental data; but also we are able to suggest a protocol for efficient experimentation to achieve better radiobiological data at a substantial saving in beam time, through a research design based on computer fitting of track theory to the experimental data, interactively, as the experiment proceeds.

The successes of track theory in predicting the outcome of a number of radiobiological experiments, including those involving deliberate mixing of gamma-rays and neutrons in different proportions, and in the calculation of RBE-Dose relations for neutrons, of different energies, and for spread beams of He ions, as perceived in in-vivo experiments, has stimulated us to simplify our RBE calculations. 
In this effort we have made use of the concept of irradiation equivalence - that it is possible to specify a track-segment irradiation yielding the same survival, the same ion-kill and gamma-kill dose fractions, as the mixed radiation field (say, neutrons of a spectrum of energies) of interest. With this simplification we have been able to write a formulary for the survival, RBE, OER, $D_{x}$ lequivalent dose of $x$-rays yielding the same survival) for arbitrarily mixed radiation environments (neutrons plus gamma-rays, plus stopped pions, for example). To illustrate its simplicity, we have programmed this algorithm for the HP-65 pocket programmable calculator. The program can be stored on a magnetic card. The dose, and the fractions of the dose in each mode (neutrons, gamma-rays, and so on) can be entered in a set of storage registers. The program will evaluate dose at a given survival level, survival at a given dose level, RBE, and $D_{x}$. If the calculation is repeated for aerobically and for anoxically irradiated cells, it will yield OER. Its results agree with available data for both in vitro and in vivo systems. We expect this practical offshoot of these investigations of the theory of $\mathrm{RBE}$ to be of value in radiobiological investigations, as well as for the problems of the health physicist and the clinical physicist interested in treatment planning.

At this stage it. must be borne in mind that the calculations made following this formulation are largely in the nature of predictions, for while our results agree with experiment in those cases where experiments have been done, the experimental tableau is rather incomplete. We hope that the existence of our simplification of track theory calculations will stimulate experimental tests of the theory. 